Sigmar de Mello Rode(a), Xiomara Gimenez $^{(b)}$, Victoria Criado Montoya $^{(b)}$, Mariel Gómez ${ }^{(c)}$, Silvia Lopez de Blanc ${ }^{(d)}$, Marco Medina ${ }^{(e)}$, Elmer Salinas(f), Janeth Pedroza(g), Rosi Maria Zaldivar-Chiapa ${ }^{(h)}$, Claudio Mendes Pannuti ${ }^{(i)}$, José Roberto Cortelli(i), Rui Vicente Oppermann ${ }^{(k)}$

(a) Department of Dental Materials and Prosthesis, School of Dentistry, Univ Estadual Paulista UNESP, São José dos Campos, SP, Brazil.

(b) Department of Periodontology, School of Dentistry, Univ Central de Venezuela, Los Chaguaramos, Caracas, Venezuela.

(c) Department of Periodontology, School of Dentistry, Univ Maimónides, Ciudad Autónoma de Buenos Aires, Argentina.

(d) Department of Oral Pathology, School of Dentistry, Univ Nacional de Córdoba - UNC, Córdoba, Argentina.

(e) Department of Periodontology, School of Dentistry, Univ Central del Ecuador, Quito, Ecuador.

(f) Department of Periodontology, School of Dentistry, Univ de San Martín de Porres, San Luis, Lima, Perú.

(g) Department of Periodontology, School of Dentistry, Pontificia Univ Javeriana, Bogotá, Colombia.

(h) Department of Periodontology, School of Dentistry, Univ Autónoma de Nuevo León - UANL, San Nicolás de Los Garza, Nuevo León, México.

(i) Periodontology Department, School of Dentistry, Univ de São Paulo - USP, São Paulo, SP, Brazil.

(i) Periodontology Department, School of Dentistry, Univ de Taubaté - UNITAU, Taubaté, SP, Brazil.

(k) Periodontology Department, School of Dentistry, Univ Federal do Rio Grande do Sul - UFRGS, Porto Alegre, RS, Brazil.

Declaration of Interests: The authors certify that they have no commercial or associative interest that represents a conflict of interest in connection with the manuscript.

Corresponding Author:

Sigmar de Mello Rode

E-mail: sigmarrode@uol.com.br

Submitted: Aug 30, 2012

Accepted for publication: Sep 11, 2012

Last revision: Oct 19, 2012

\section{Daily biofilm control and oral health: consensus on the epidemiological challenge - Latin American Advisory Panel}

\begin{abstract}
Our understanding of dental plaque biofilm has evolved since the nonspecific plaque hypothesis that considered plaque as a nonspecific mass of native microorganisms that, because of lack of oral hygiene, builds up in proportions great enough to overcome the host resistance threshold and affect the tooth structure and tooth supporting tissues. A great diversity of microorganisms-over 700 species-was detected in the oral cavity, and evidence shows that the investigation of specific microorganisms or associations of microorganisms as etiological agents for periodontal diseases and caries is not a simplistic approach. Although clinical evidence shows that oral mechanical hygiene is fundamental to prevent and control caries and periodontal disease, it is important to highlight that optimal control is not achieved by most individuals. Thus the complementary use of chemotherapeutic agents has been investigated as a way to overcome the deficiencies of mechanical oral hygiene habits, insofar as they reduce both plaque formation and gingival inflammation, and represent a valid strategy to change the biofilm and maintain dental and periodontal health. The role of the dental professional is to monitor patients and offer them the best recommendations to preserve oral health throughout their life. With this in mind, chemical control should be indicated as part of daily oral hygiene, together with mechanical procedures, for all individuals who present supragingival and/or subgingival biofilm, taking into account age, physical and/or psychological limitations, allergies, and other factors.
\end{abstract}

Descriptors: Oils; Cetylpyridinium; Mouthwashes; Dental Plaque; Gingivitis.

\section{Introduction}

The Latin American Oral Health Advisory Panel is composed of several Latin American dentists with different specialties. They get together annually to discuss issues related to oral health, such as daily control of biofilm, aiming to establish a rationale and consensus regarding oral health.

The topics to be evaluated are determined according to preestablished presentations and roundtable discussions, and are then assessed for proper scientific foundation, after which they are presented to the dental com- 
munity.

The topics chosen for discussion this year were:

- biofilm complexity,

- mechanical methods of oral hygiene,

- importance of daily chemotherapeutic biofilm control,

- choice of the active ingredient for daily use to control plaque and gingivitis, and

- indications and contraindications of the daily use of mouthwashes.

The conclusions are presented below.

\section{Biofilm complexity}

Our understanding of dental plaque biofilm has evolved since the nonspecific plaque hypothesis that considered plaque as a nonspecific mass of native microorganisms that, because of lack of oral hygiene, builds up in proportions great enough to overcome the host resistance threshold and affect the tooth structure and tooth supporting tissues. This hypothesis does not focus on the importance of the dental plaque composition; it assumes that there is a direct relationship between the number of plaque bacteria and its pathological consequences. ${ }^{1}$

The specific dental plaque hypothesis posits that periodontal pathologies are caused by certain microorganisms, and was formulated based on clinical observations where gingivitis is associated to permanent plaque buildup that progresses to periodontitis. Studies working with this hypothesis found a higher number of selected pathogens in periodontal disease and a fewer number in healthy sites. Longitudinal studies also found a higher risk of periodontal destruction in sites colonized by these microorganisms. $^{2}$

The predominant colonizers during the early stages of subgingival biofilm accumulation are $A c$ tinomyces and Streptococcus, whereas most of the secondary colonizers tend to be more pathogenic, such as Porphyromonas gingivalis, Tannarella forsythia, Treponema denticola, Fusobacterium nucleatum and Actinobacillus (Aggregatibacter) actinomycetemcomitans. Furthermore, a number of secondary colonizers, specifically F. nucleatum and $P$. gingivalis, may also be found in the early stages of biofilm accumulation, contributing to the development of a polymicrobial consortium.

Kuboniwa and Lamont ${ }^{3}$ defined a surface configuration having multivalent adhesins, with multiple adhesins with different specificities, as found in $P$. gingivalis, for example, which favors community development.

A great diversity of microorganisms-over 700 species-has been detected in the oral cavity, ${ }^{4}$ and evidence shows that the investigation of specific microorganisms or associations of microorganisms as etiological agents of periodontal diseases and caries is not a simplistic approach. Thus dental plaque must be studied as a biofilm, as communities composed of microorganisms, and not as individual pathogens, in order to understand its biology and functional implications. ${ }^{5}$

Donlan and Costerton ${ }^{6}$ defined biofilm as a sessile microbiological community characterized by cells adhered to a substrate, to an interface or to each other, embedded in an extracellular polymeric substance matrix that produces and presents an altered phenotype, in terms of growth rate and gene transcription. The basic structure of these microbiological communities is described as being universal, insofar as its structural unit is the colony of bacteria. In their structured micro canals for water and nutrient flow, the biofilms present basic processes among the micro-colonies, such as quorum sensing, anti-bacterial resistance, and detachment. These may help us understand their physiological interactions. ${ }^{6}$ Biofilm colony detachment may lead to the colonization of structures at a distant site, which may generate pathologies such as bacterial endocarditis. $^{7}$

Bacterial resistance is a characteristic of biofilm microorganisms. It may be caused by the difficulty of the antimicrobial agent molecules to diffuse through the biofilm matrix in order to inactivate the cells or to react with the extracellular matrix components. Antibacterial resistance of microorganisms in the biofilm may also be attributed to the slower growth of the cells when compared with planktonic cells. This slower growth results in the slower action of these agents. ${ }^{8,9}$

Bacterial communities may be influenced by 
physical and biological factors, nutrient availability, $\mathrm{pH}$ and oxy-reduction potential, as well as diet, smoking habits and the patient's overall health and oral hygiene. These determinants may change the biofilm characteristics. The changes in the periodontal microenvironment may alter the bacterial homeostasis associated with health, and trigger periodontal pathologies. ${ }^{10}$

Effective mechanical and chemical control strategies must be applied in treating hard (teeth) and soft tissues (oral mucosa and tongue)-the main reservoirs for microorganism recolonization-in order to influence biofilm composition and prevent the development of caries and periodontal disease.

\section{Mechanical methods of oral hygiene}

The evidence indicates that the bacterial plaque that builds up on the oral surfaces and its metabolism play an important role in caries, gingivitis, periodontal disease and peri-implantitis development. Mechanical plaque control interrupts supragingival biofilm development, enabling the biofilm composition to be compatible with oral health in most patients. ${ }^{11}$

A correct and adequate hygiene procedure for the teeth and oral cavity is the most effective and specific way to prevent dental caries and periodontal diseases. There is evidence that brushing associated with flossing can control dental biofilm buildup when performed adequately and systematically, at regular intervals. ${ }^{12,13}$

Should natural physiological methods (through the action of tongue, cheeks, salivary flow, etc.) become ineffective, the mechanical methods for biofilm control represent fundamental measures to prevent and control periodontal diseases. There is evidence that brushing associated with flossing and other interproximal devices can control biofilm buildup when properly performed, in a systematic manner and at regular intervals. ${ }^{12-14}$

There are several types of toothbrushes available on the market. The most accepted types used today are flexible, with round tips and soft bristles. ${ }^{15}$ The most recommended brushing technique is the "Modified Bass Technique." Both electric and manual toothbrushes may be used. These offer similar efficacy for biofilm removal, but electric toothbrushes are slightly better. ${ }^{14}$ Nevertheless, regardless of the type of toothbrush or technique, this method has been found to remove only the biofilm present on the free surfaces of the teeth (buccal, occlusal and lingual). Carious lesions, gingivitis and periodontitis start or present a higher severity in interproximal regions. When analyzed solely, the brushing technique is less effective to remove biofilm on interproximal areas, where flossing, ${ }^{16}$ as well as rubber stimulators, proximal brushes, single-bristle brushes or irrigators may be necessary. ${ }^{14-17}$

It is important to highlight that the population in general presents a low adherence to flossing ${ }^{18}$ and other interproximal devices. ${ }^{14}$ It should also be noted that mechanical or home care control of biofilm actually represents a mechanical-chemical protocol, insofar as toothpaste is associated with the toothbrush, dental floss and other interdental devices that must be customized according to the dexterity and abilities of each patient.

Unfortunately, regardless of the type of brushing or the technique used, it has been found that mechanical hygiene removes only the biofilm present on tooth surfaces; even after brushing, tongue cleaning and/or using dental floss or other interproximal devices, about $67 \%{ }^{19}$ of intraoral surfaces are not reached by brushing and flossing, and can be colonized by pathogenic microorganisms. ${ }^{20}$

A systematic review based on 6-month studies demonstrated that oral hygiene instruction associated with professional plaque control has a slight effect on gingival inflammation in adults with gingivitis $^{21}$ or periodontitis ${ }^{22}$ and must be repeated periodically. ${ }^{14}$

Although clinical evidence shows that oral mechanical hygiene is fundamental to prevent and control caries and periodontal disease, it is important to mention that optimal control is not achieved for most individuals. This could be due to lack of motivation or of manual dexterity, which lead to noncompliance with professional recommendations regarding oral hygiene procedures. ${ }^{23,24}$

The socioeconomic level and knowledge of the disease process may also influence the pattern and 
quality of oral hygiene. ${ }^{25,26}$ The complementary use of chemotherapeutic agents has been investigated as a way to overcome the deficiencies of mechanical oral hygiene habits, since they reduce plaque formation and gingival inflammation, and represent valid strategies to change the biofilm and maintain dental and periodontal health. ${ }^{27}$ Moreover, the teeth represent only $25 \%$ of the oral cavity, the rest of which practically does not benefit from mechanical oral hygiene by brushing, flossing or other interdental devices. ${ }^{19}$

\section{Importance of the daily chemotherapeutic control of biofilm}

Bacteria are normal inhabitants of the oral cavity. Certain species are capable of causing periodontal disease and caries, the two most common oral pathologies for dentists on a daily basis in their dental practice. Consequently, the qualitative or quantitative change of this microbial population plays an important role in both the active treatment of these pathologies and the maintenance of oral health.

Despite the great efforts made by oral health professionals, caries and periodontal diseases are highly prevalent in the population. They continue to be a great concern not only to professionals but also to patients. As recently noted by the World Health Organization (WHO), these diseases are a public health concern worldwide, affecting developed countries with increasingly greater frequency, ${ }^{25}$ as well as developing countries, ${ }^{26,28}$ especially among poor communities.

Romanelli et al..$^{29}$ reported that $94 \%$ of adult patients in Argentina presented some degree of gum disease; similar percentages have been reported in most Latin American countries. The high incidence of periodontal disease among adults indicates that, in most of these cases, daily oral hygiene could and should be improved extensively. ${ }^{30}$

Studies show that periodontal disease can be prevented and minimized through carefully supervised dental biofilm control programs. ${ }^{30}$ Mechanical methods used on a daily basis have been considered as the best way to eliminate biofilm by patients, al- though some residual bacteria remain in the oral cavity. This is partially due to inadequate brushing and flossing techniques. Even well-trained patients commonly have dental health problems in areas of difficult access and posterior regions of the mouth. The mechanical methods for elimination of dental biofilm require time, motivation and manual dexterity; these factors limit the adequate practice of daily oral hygiene and suggest that other strategies are needed. ${ }^{31}$

Mouthwashes with chemotherapeutic agents may represent an important complement to mechanical methods in periodontal disease prevention and treatment. ${ }^{32}$ Accordingly, the criteria used to select dental products must be evaluated by dental professionals, not only regarding the efficacy of these products but also regarding the individual preferences and characteristics of patients. ${ }^{33}$

The objective is to change the amount and/or quality of the supragingival and subgingival plaque in a way that the immune system can control the bacteria and prevent periodontal disease progression. The recommended mouthwashes are those with proven scientific evidence of efficacy, safety, and significant effect in both the short and the long term against biofilm, gingivitis and, ideally, against caries, and should also demonstrate efficacy against a wide variety of Gram+ and Gram- bacterial species. ${ }^{23-36}$

Several studies have demonstrated that most patients do not clean biofilm effectively in interdental areas, or even maintain optimal long-term oral hygiene levels, and have observed a gingivitis prevalence ranging from $85 \%$ to $90 \%$ in the Latin American population, in disabled individuals or even those having no special impairment. ${ }^{26}$ This situation is aggravated in elderly adults, where dental biofilm retention is a problem because of the existence of defective restorations, exposed root surfaces, or others reasons. Moreover, most of the members of this group have difficulty removing dental biofilm mechanically, because of reduced manual dexterity, or because of severe physical limitations, associated with conditions such as arthritis, stroke or Parkinson's disease, which reduce their ability to use brushing and flossing techniques adequately. Some systemic diseases and xerostomia, induced by some 
medications, can trigger and aggravate existing dental problems, while the motivation for effective oral hygiene may be lessened in those who are weak or functionally dependent. ${ }^{26,34}$

The limitations of the elderly, and their acceptance of and adherence to different techniques and oral care procedures, suggest that certain auxiliary means should be implemented, such as mouthwashes, which help improve the mechanical control measures of oral biofilm. ${ }^{35}$

Mentally ill patients and patients with Down syndrome represent a population group with risk factors that predispose them to oral disease and that could be mitigated with the implementation of preventive measures. Some authors suggest that mouthwashes may be an effective response to the oral hygiene problem in disabled individuals. ${ }^{36}$

Ideally, an effective antiseptic must penetrate the biofilm. ${ }^{37}$ Recent studies have suggested that bacterial phenotypes may change when the microorganisms turn from a planktonic condition (in suspension or freely floating) to a sessile condition (as part of a biofilm).

When bacteria grow in the biofilm, they manifest a different phenotype in comparison with the planktonic form. The phenotype of the bacteria in biofilm is different; namely, it is more resistant to several antimicrobials, and this condition is maintained when the bacteria are detached from the biofilm. ${ }^{38}$ For this reason, the efficacy of any mouthwash depends not only on its antimicrobial properties, typically demonstrated in in vitro studies, but also on its ability to penetrate the biofilm, as also seen through in vivo studies. ${ }^{39}$ Mouthwashes effective against planktonic bacteria may not be effective against bacteria within the biofilm. ${ }^{40,41}$

It should be noted that bacteria within the biofilm present a higher resistance to distinct antimicrobials; therefore, it is questioned if the products that are available on the market are really effective. In fact, new in vitro research is being carried out to determine the efficacy of antimicrobial agents against biofilms. Most of the available studies published on mouthwashes marketed today report on chlorhexidine and essential oils, showing their ability to penetrate the biofilm and produce an effective bactericidal action..$^{42}$

However, in no case may the mechanical control of biofilm be replaced when the third step of the oral hygiene procedure (use of a rinse) acts as a coadjutant. The available rinses, particularly chlorhexidine and essential oils, can penetrate the biofilm (as seen through in vivo studies) to eliminate bacteria, diminishing its formation and gingivitis development, even in areas of difficult access, while offering excellent safety and tolerability characteristics.

Dentists should suggest to their patients that they perform the three steps of the oral hygiene procedure, i.e., brushing, flossing and rinsing, after each meal, to maintain long-term oral health. ${ }^{32,33}$

\section{Choosing the active ingredient for daily use in controlling plaque and gingivitis}

If we recognize that the oral mucosa represents $80 \%$ of the total surface of the mouth and that it can serve as a reservoir for different periodontal pathogens, which may be transferred to and from the tooth surface and gingival sulcus, the use of antimicrobial substances, together with mechanical methods for biofilm control, may play an important role in reducing these pathogens in reservoirs left unreached by brushing and flossing. ${ }^{43}$ The evidence suggests that the ideal requisites for chemical control agents are effectiveness, substantivity, safety and stability. ${ }^{44}$

The active ingredients in mouthwashes have a broad spectrum of action, and are effective against a great variety of bacteria, viruses and fungi. These chemical agents must demonstrate efficacy on microorganisms that cause gingivitis and periodontitis, both through in vitro and in vivo studies, based on scientific evidence supporting their long-term efficacy and safety.

The mouthwashes accepted by the American Dental Association (ADA) have proven effective in preventing and reducing biofilm and gingivitis. In order to be accepted, the products must meet certain scientific criteria, mainly in regard to destruction, inhibition or modification of biofilm, and prevention of, or at least $20 \%$ reduction in, gingivitis. They 
must be tested in at least two 6-month independent, randomized clinical trials with a placebo control group; they must include subjects with mild to moderate gingivitis, with no adverse events; and they must have statistically significant results in reducing plaque and gingivitis. ${ }^{45} \mathrm{Up}$ to now only three active ingredients from different products have obtained the ADA seal of acceptance:

- chlorhexidine digluconate (for treatment short term),

- essential oils (for daily use - long term) and

- triclosan (present in dentifrices). ${ }^{46}$

The antibacterial effect of these chemical agents depends on other characteristics such as substantivity, which can be defined as prolonged in vivo action measured in hours. ${ }^{47}$ Each patient's needs must be taken into account separately when prescribing an antimicrobial agent.

Chlorhexidine digluconate is a cationic bisbiguanide agent with a broad antimicrobial spectrum. It is considered the gold standard for the chemical control of biofilm, ${ }^{48}$ primarily because of its high substantivity, and secondly because of its antimicrobial activity. It is capable of reducing dental biofilm by up to $71 \%$, and gingival inflammation by up to $45 \%$, compared to placebo. ${ }^{49}$

It is highly effective as an adjunct to professional and home care procedures in controlling periodontal diseases. It is prescribed when the patient is unable to perform mechanical control procedures for any reason, thereby compromising oral hygiene. It is important to remember that although chlorhexidine has been shown to have the greatest antiplaque effects, long-term use (more than 20 days) is not recommended, because of undesirable side effects, such as extrinsic tooth staining and calculus buildup, along with dysgeusia, which can compromise treatment results. ${ }^{48,50-52}$

The maintenance of gingival health in patients with a deficiency in the mechanical control of biofilm is an indicator for recommending a chemotherapeutic for daily home care oral hygiene procedures. The antiplaque and antigingivitis action of a chemical agent for daily use must not cause adverse events and must not change the oral microbiota. ${ }^{53}$ Of all the daily mouthwashes available on the market, the most studied product is one having a fixed combination of four essential oils (EOs) with a history of over 100 years as a chemotherapeutic agent, and with scientific based superiority through in vitro and in vivo short- and long-term studies on biofilm control. ${ }^{50,54}$ The scientific literature supports the evidence that essential oils have a broad antimicrobial effect against aerobic and anaerobic microorganisms, Gram+ and Gram- bacteria, and against yeast and fungi. They also promote a reduction in both bacterial endotoxins and biofilm pathogenicity, and penetrate deeper into the biofilm. ${ }^{53,55-62}$

Fine et al. ${ }^{63}$ investigated the effect of using an essential-oil-containing mouthwash and its effect on periodontal pathogenic bacteria levels in individuals presenting mild to moderate periodontal disease. They found that the levels of each subgingival microorganism were significantly lower at 14 days after using an essential-oil-containing mouthwash, in comparison with the control.

Cortelli et al. ${ }^{64}$ analyzed the microbial and salivary clinical effect of rinses, and concluded that the essential oils offered benefits in reducing plaque and gingival inflammation without changing the basic salivary patterns in patients with advanced periodontal disease.

Charles et al. ${ }^{65}$ and Sharma et al. ${ }^{66}$ compared the long-term efficacy of cetylpyridinium chloride (CPC) and mouthrinses containing essential oils (EO) for plaque and gingivitis control. The results showed a statistically significant difference in the modified gingival index (MGI) and in the plaque index (PI), when using EO as compared to CPC. The plaque reduction after 6 months was $56 \%$ higher for EO, compared with CPC, concluding that the EO showed highly significant efficacy in long-term reduction of plaque and gingivitis.

Gunsolley $^{50}$ presented a study to evaluate the evidence of the antiplaque and antigingivitis effect of mouthwashes and to determine their clinical relevance. He concluded that cetylpyridinium chloride, chlorhexidine and essential oils are effective agents to reduce plaque and gingival indexes. Chlorhexidine offered the highest reduction in these indexes, followed by essential oils and cetylpyridinium chlo- 
ride.

Van Leeuwen et al. ${ }^{51}$ published a literature review to systematically evaluate the effects of mouthwashes containing essential oils versus chlorhexidine, in regard to plaque and gingival inflammation parameters, through 6-month studies. The authors concluded that chlorhexidine presented better results than essential oils for dental biofilm control, and that essential oils did not differ from chlorhexidine in the long term for gingival inflammation control, and was therefore a good alternative. Chlorhexidine presented adverse events, such as tooth and soft tissue staining, after long-term use. The authors concluded that chlorhexidine is the agent of choice for dental biofilm control in post-operative procedures, and that essential oils are a good and dependable alternative for controlling gingival inflammation. ${ }^{51}$

Cetylpyridinium chloride is another chemical control agent used in mouthwashes for therapeutic benefit. Special care must be taken when choosing the correct formula, in order to guarantee a high degree of bioavailability of the active agent on which dental biofilm inhibition and inflammation reduction depend..$^{50,54}$

It is important that the professional determine the patient's specific needs before recommending a chemical agent to control biofilm, as a complementary measure for oral hygiene mechanical methods. Several factors must be considered, insofar as dexterity and patient compliance are the most important in guiding the suggestions and instructions offered by the dental professional. Dentists must know their patients' weaknesses and set guidelines for them, to which patients must commit with impactful actions to keep up their biofilm control routine. Thus, the maintenance of the gingival health status of patients with a less than optimal mechanical control of dental biofilm is an indicator for recommending chemical control to supplement daily oral hygiene practices.

\section{Indications and contraindications for using mouthwashes daily}

The use of chemical agents for biofilm control has been studied as a way to overcome the short- comings of mechanical oral habits in order to control the most frequent oral diseases, such as caries and periodontal disease. For this reason, they are indicated mainly for patients with non-controlled risk factors (sugar-rich diet, poorly positioned teeth, orthodontics, and prostheses or restorations that are defective owing to inadequate dental materials). ${ }^{67-69}$ They are also indicated for individuals who are disabled or have dexterity problems, children up to 6 years of age and the elderly. Other indications include pre- and post-operative procedures for preventing possible surgical complications, for avoiding pneumonia by aspiration of the oral microbiota, for elderly patients with oral-pharyngeal diseases, ${ }^{70}$ for reducing symptomatology in oral lesions such as aphthous ulcers ${ }^{71,72}$ and for wound tissue healing.

The dentist should decide what the best agents are, how long they will be used and what are the most indicated formulations. Chlorhexidine-containing mouthrinses at $0.12 \%$ or $0.2 \%$ are indicated for short time periods ( 1 to 6 weeks). It is important to note that the clinical effect of chlorhexidine is higher when the calculus and dental biofilm are previously removed. Risk analysis should be conducted for long-term use because of adverse events in relation to benefits. Patients should be instructed about the possibility of adverse events, and also about the possible need for professional stain removal from teeth and restorations, as well as calculus removal if present after rinsing with this mouthwash.

The risk of accidental intoxication ${ }^{73-75}$ may occur in children because of their lack of dexterity, which may cause swallowing of the chemical agents, and also because of alcohol ingestion. Moreover, alcohol-containing mouthwashes are also contraindicated for patients who are addicted to alcohol or recovering from alcohol addiction. ${ }^{76}$

There is evidence of a rise in the daily use of mouthwashes by the population in Latin America, as compared with populations in the United States and Europe, where this habit is more widespread. There is a great variety of formulations available today, but not all are backed up by scientific evidence to confirm their efficacy and safety. Today's availability of efficient formulations with significantly lower adverse events represents a change in options 
for chemically controlling biofilm, as compared with the past, when chlorhexidine was the only agent capable of inhibiting plaque and gingivitis. Dental professionals should consider if chemical control must be used as a coadjutant or as an essential part of the recommended protocol for adequate oral hygiene.

Making use of a complete and adequate oral hygiene program that includes chemical control is well-supported by scientific knowledge and is effective in reducing gingival inflammatory levels.

Indicating chemotherapeutic agents universally for biofilm control is still questioned, considering that some people associate their gingival health with traditional mechanical control procedures. This is an epidemiological concern, since this recommendation of using chemical control will benefit most of the population. Similar arguments were used in the past regarding the addition of fluoride in public water supplies.

It is important to remember that, in many cases, antimicrobial rinses, when used as the third step of an oral hygiene regimen, should not be recommended as a solution for a patient lacking interest or motivation to adequately perform the required mechanical procedures. A pertinent line of reasoning is that people who do not perform the mechanical steps properly do not rinse adequately, thus requiring supervision and guidance. Similarly, one cannot expect that using only chemical control is enough to remove or do away with biofilm, or else prevent gingivitis. Clinical studies show that despite the use of effective formulations, there is still a remnant of biofilm or gingival inflammation that must be dealt with. That remaining biofilm will likely be removed only by improving the mechanical control patterns, and better results are observed with the association of chemical control with adequate mechanical control of the biofilm. This defines the cycle of proper oral control.

Oral hygiene procedures require constant guidance throughout life's different stages. Factors include change in habits, social behaviors associated with age, socioeconomic position and other determinant variables responsible for the individual's health. The role of the dental professionals is to monitor patients and offer them the best solutions for oral health preservation throughout their lives. With this in mind, chemical control as part of the daily oral hygiene, together with mechanical procedures, must be indicated for all individuals who present supragingival and/or subgingival biofilm, taking into account age, physical and/or psychological limitations, allergies, and other factors. ${ }^{77}$

\section{Final considerations}

Effective mechanical and chemical control strategies must be applied in treating hard (teeth) and soft tissues (oral mucosa and tongue) - the main reservoirs for microorganism recolonization-in order to influence biofilm composition and prevent the development of caries and periodontal disease.

Although clinical evidence shows that oral mechanical hygiene is fundamental to prevent and control caries and periodontal disease, it is important to highlight that optimal control is not achieved by most individuals. This may be attributed to lack of motivation or manual dexterity, responsible for non-compliance in following recommendations for cleaning the teeth. With this in mind, the complementary use of chemotherapeutic agents has been investigated as a way to overcome the deficiencies of mechanical oral hygiene habits, since they reduce both plaque formation and gingival inflammation, and also represent a valid strategy to alter the biofilm and maintain dental and periodontal health. Oral hygiene procedures represent a long-term commitment and require constant guidance throughout life's different phases, which may call for a change in habits, age-related social behaviors, socioeconomic position and other determinant variables responsible for the individual's health. The role of the dental professional is to monitor patients and offer them the best recommendations to preserve oral health throughout their life. With this in mind, chemical control must be indicated as part of daily oral hygiene, together with mechanical procedures, for all individuals who present supragingival and/or subgingival biofilm, taking into account age, physical and/or psychological limitations, allergies, and other factors. 


\section{References}

1. Theilade E. The non-specific theory in microbial etiology of inflammatory periodontal diseases. J Clin Periodontol. 1986;13(10):905-11.

2. Loesche WJ. Clinical and microbiological aspects of chemotherapeutic agents used according to the specific plaque hypothesis. J Dent Res. 1979 Nov;58(12):2404-12.

3. Kuboniwa M, Lamont RJ. Subgingival biofilm formation. Periodontol 2000. 2010 Dec;52(1):38-52.

4. Paster BJ, Boches SK, Galvin JL, Ericson RE, Lau CN, Levanos VA, et al. Bacterial diversity in human subgingival plaque. J Bacteriol. 2001 Jun;183(12):3770-83.

5. Marsh PD. Dental Plaque as a microbial biofilm. Caries Res. 2004 May-Jun;38(3):204-11.

6. Donlan RM, Costerton JW. Biofilms: survival mechanisms of clinically relevant microorganisms. Clin Microbiol Rev. 2002 Apr;15(2):167-93.

7. Lewandowski Z. Structure and function of biofilms. In: Evans LV, editor. Biofilms: recent advances in their study and control. Newark: Harwood Academic Publishers; 2000. p. 1-17.

8. Amorena B, Gracia E, Monzón M, Leiva J, Oteiza C, Perez $\mathrm{M}$, et al. Antibiotic susceptibility assay for Staphylococcus aureus in biofilms developed in vitro. J Antimicrob Chemother. 1999 Jul;44(1):43-55.

9. Chuard C, Vaudaux CP, Waldovogel FA, Lew DP. Susceptibility of Staphylococcus aureus growing on fibronectin-coated surfaces to bactericidal antibiotics. Antimicrob. Agents Chemother. 1993 Apr;37(4):625-32.

10. Marsh PD, Devine DA. How is the development of dental biofilms influenced by the host?. J Clin Periodontol. 2011 Mar;38 Suppl 11:28-35.

11. Claydon NC. Current concepts in toothbrushing and interdental cleaning. Periodontol 2000. 2008 Oct;48(1):10-22.

12. Löe $H$, Theilade $E$, Jensen SB. Experimental gingivitis in man. J Periodontol. 1965 May-Jun;36:177-87.

13. Ximénez-Fyvie LA, Haffajee AD, Som S, Thompson M, Torresyap G, Socransky SS. The effect of repeated professional supragingival plaque removal on the composition of the supra and subgingival microbiota. J Clin Periodontol. 2000 Sep;27(9):637-47.

14. Van der Weijden F, Slot DE. Oral hygiene in the prevention of periodontal diseases: the evidence. Periodontol 2000. 2011Feb;55(1):104-23.

15. Drisko C, Henderson R, Yancy J. A review of current toothbrush bristle endo-rounding studies. Compend Contin Educ Dent. 1995 Jul;16(7):694, 696, 698.

16. Axelsson P, Albandar JM, Rams TE. Prevention and control of periodontal diseases in developing and industrialized nations. Periodontol 2000. 2002 Apr;29(1):235-46.

17. Bergenholtz A, Björne A, Vikström B. The plaque-removing ability of some common interdental aids. An intraindividual study. J Clin Periodontol. 1974;1(3):160-5.
18. Wilson TG Jr. How patient compliance to suggested oral hygiene and maintenance affect periodontal therapy. Dent Clin North Am. 1998 Apr;42(2):389-403.

19. Collins LM, Dawes C. The surface area of the adult human mouth and thickness of the salivary film covering the teeth and oral mucosa. J Dent Res. 1987 Aug;66(8):1300-2.

20. Cortelli JR, Aquino DR, Cortelli SC, Fernandes CB, Carvalho-Filho J, Franco GC, et al. Etiological analysis of initial colonization of periodontal pathogens in oral cavity. J Clin Microbiol. 2008 Apr;46(4):1322-9.

21. Van der Weijden GA, Hioe KP. A systematic review of the effectiveness of self-performed mechanical plaque removal in adults with gingivitis using a manual toothbrush. J Clin Periodontol. 2005; 32 Suppl 6:214-28.

22. Hujoel PP, Cunha-Cruz J, Loesche WJ, Robertson PB. Personal oral hygiene and chronic periodontitis: a systematic review. Periodontol 2000. 2005 Feb;37(1):29-34.

23. Teles RP, Teles FR. Antimicrobial agents used in the control of periodontal biofilms: effective adjuncts to mechanical plaque control?. Braz Oral Res. 2009 Jun;23 Suppl 1:39-48.

24. Maltz M, Jardim JJ, Alves LS. Health promotion and dental caries. Braz Oral Res. 2010;24 Suppl 1:18-25

25. Li Y, Lee S, Hujoel P, Su M, Zhang W, Kim J, et al. Prevalence and severity of gingivitis in American adults. Am J Dent. 2010 Feb;23(1):9-13.

26. Gjermo P, Rösing CK, Susin C, Oppermann R. Periodontal diseases in Central and South America. Periodontol 2000. 2002 Apr;29(1):70-8.

27. Apatzidou DA. Modern approaches to non-surgical biofilm management. Front Oral Biol. 2012;15:99-116.

28. Oppermann RW. An overview of the epidemiology of periodontal diseases in Latin America Brazilian. Braz Oral Res. 2007;21 Suppl 1:9-15.

29. Romanelli H, Gonzalez y Rivas M, Chiappe V, Gómez M, Macchi R. Peridontal treatment needs in Argentine adult subjects. Acta Odontol Latinoam. 2007;20(1):39-47.

30. Axelsson P, Lindhe J. Efficacy of mouthrinses in inhibiting dental plaque and gingivitis in man. J Clin Periodontol. 1987 Apr;14(4):205-12.

31. DePaola LG, Overholser CD, Meiller TF, Minah GE, Niehaus C. Chemotherapeutic inhibition of supragingival dental plaque and gingivitis development. J Clin Periodontol. 1989 May;16(5):311-5.

32. Bouwsma OJ. The status, future, and problems of oral antiseptics. Curr Opin Periodontol. 1996;3:78-84.

33. Baker K. Mouthrinses in the prevention and treatment of periodontal disease. Curr Opin Periodontol. 1993;1:89-96.

34. Kerry GJ. Supportive periodontal treatment. Periodontol 2000. 1995 Oct;9(1):176-185.

35. Criado V, Tawse-Smith A. Compliance \& dexterity, factors to consider in home care and maintenance procedures. Braz Oral Res. 2007;21 Suppl 1:34-8. 
36. Francis JR, Addy M, Hunter B. A comparison of three delivery methods of chlorhexidine in handicapped children. II. Parent and house parent preferences. J Periodontol. 1987 Jul;58(7):456-9.

37. Serrano-Granjer J, Herrera D. La placa dental como biofilm: cómo eliminarla?. Rev Actual Odontoestomatol Esp. 2005 JulAug;10(4):431-9.

38. Pan P, Barnett ML, Coelho J, Brogdon C, Finnegan MB. Determination of the in situ bactericidal activity of an essential oil mouthrinse using a vital stain method. J Clin Periodontol. 2000 Apr;27(4):256-61.

39. Enrile de Rojas FJ, Santos-Alemany A. Colutorios para el control de placa y gingivitis basados en la evidencia científica. Rev Actual Odontoestomatol Esp. 2005 Jul-Aug;10(4):445-52.

40. Barnett ML. The role of therapeutic antimicrobial mouthrinses in clinical practice: control of supragingival plaque and gingivitis. J Am Dent Assoc. 2003 Jun;134(6):699-704.

41. Ouhayoun JP. Penetrating the plaque biofilm: impact of essential oil mouthwash. J Clin Periodontol. 2003:30 Suppl 5:10-2

42. Fine DH, Furgang D, Barnett ML. Comparative antimicrobial activities of antiseptic mouthrinses against isogenic planktonic and biofilm forms of Actinobacillus actinomycetemcomitans. J Clin Periodontol. 2001 Jul;28(7):697-700.

43. Mager DL, Ximenez-Fyvie LA, Haffajee AD, Socransky SS. Distribution of selected bacterial species on intraoral surfaces. J Clin Periodontol. 2003 Jul;30(7):644-65.

44. Fischman SL. Oral hygiene products: how far have we come in 6000 years. Periodontol 2000. 1997 Oct;15(1):7-14.

45. Imrey PB, Chilton NW, Pihlstrom BL, Proskin HM, Kingman A, Listgarten MA, et al. Recommended revisions to American Dental Association guidelines for acceptance of chemotherapeutic products for gingivitis control. J Periodontal Res. 1994 Jul;29(4):299-304.

46. American Dental Association [homepage on the Internet]. About the ADA seal of acceptance. [cited 2012 Mar 30]. Available from: http://www.ada.org.

47. Eley BM. Antibacterial agents in the control of supragingival plaque - a review. Br Dent J. 1999 Mar;186(6):286-96.

48. Löe H, Schiott CR. The effect of mouthrinses and topical application of chlorhexidine on the development of dental plaque and gingivitis in man. J Periodontal Res. 1970;5(2):79-83.

49. Paraskevas S. Randomized controlled clinical trials on agents used for chemical plaque control. Int J Dent Hyg. 2005 Nov;3(4):162-78

50. Gunsolley JC. Clinical efficacy of antimicrobial mouthrinses. J Dent. 2010 Jun;38 Suppl 1:S6-10.

51. Van Leeuwen MP, Slot DE, Van der Weijden GA. Essential oils compared to chlorhexidine with respect to plaque and parameters of gingival inflammation: a systematic review. J Periodontol. 2011Feb;82(2):174-94.

52. Jones CG. Chlorhexidine: is it still the gold standard? Periodontol 2000. 1997 Oct;15(1):55-62.
53. Minah GE, DePaola LG, Overholser CD, Meiller TF, Niehaus C, Lamn RA, Ross NM, Dills SS. Effects of 6 months use of an antiseptic mouthrinse on supragingival dental plaque microflora. J Clin Periodontol. 1989 Jul;16(6):347-52.

54. Gunsolley JC. A meta-analysis of six month studies of antiplaque and antigingivitis agents. J Am Dent Assoc. 2006 Dec;137(12):1649-57.

55. Pitts G, Brogdon C, Hu L, Masurat T, Pianotti, Schumann P. Mechanism of action of an antiseptic, anti-odor mouthwash. J Dent Res. 1983 Jun;62(6):738-42.

56. Kubert D, Rubin M, Barnett ML, Vincent JW. Antiseptic mouthrinse-induced microbial cell surface alterations. Am J Dent. 1993 Dec;6(6):277-9.

57. Ross NM, Charles CH, Dills SS. Long- term effects of Listerine antiseptic on dental plaque and gingivitis. J Clin Dent. 1989 Spring;1(4):92-5.

58. DePaola LG, Minah GE, Overholser CD, Meiller TF, Charles $\mathrm{CH}$, Harper DS, et al. Effect of an antiseptic mouthrinse on salivary microbiota. Am J Dent. 1996 Jun;9(3):93-5.

59. Fine DH, Furgang D, Lieb R, Korik I, Vincent JW, Barnett ML. Effects of sublethal exposure to an antiseptic mouthrinse on representative plaque bacteria. J Clin Periodontol. 1996 May;23(5):444-51.

60. Fine DH, Letizia J, Mandel ID. The effect of rinsing with Listerine antiseptic on the properties of developing dental plaque. J Clin Periodontol. 1985 Sep;12(8):660-6.

61. Fine DH, Furgang D, Barnett ML. Comparative antimicrobial activities of antiseptic mouthrinses against isogenic planktonic and biofilm forms of Actinobacillus actinomycetemcomitans. J Clin Periodontol. 2001 Jul;28(7):697-700.

62. Pan P, Barnett ML, Coelho J, Brogdon C, Finnegan MB. Determination of the in situ bactericidal activity of an essential oil mouthrinse using a vital stain methodet. J Clin Periodontol. 2000 Apr;27(4):256-61.

63. Fine DH, Markowitz K, Furgang D, Goldsmith D, Ricci-Nittel $\mathrm{D}$, Charles $\mathrm{CH}$, et al. Effect of rinsing with an essential oilcontaining mouthrinse on subgingival periodontophathogens. J Periodontol. 2007 Oct;78(10):1935-42.

64. Cortelli JR, Aquino DR, Cortelli SC, Fernandes CB, Carvalho-Filho J, Franco GC, et al. Etiological analysis of initial colonization of periodontal pathogens in oral cavity. J Clin Microbiol. 2008 Apr;46(4):1322-9.

65. Charles CH, Mostler KM, Bartels LL, Mankodi SM. Comparative antiplaque and antigingivitis effectiveness of a cholrhexidine and an escential oil mouthrinse: 6-month clinical trial. J Clin Periodontol. 2004 Oct;31(10):878-84.

66. Sharma NC, Araujo M, Wu MM, Qaqish J, Charles CH. Superiority of an essential oil mouthrinse when compared with a $0.05 \%$ cetylpyridinium chloride containing mouthrinse: a six-month study. Int Dent J. 2010 Jun;60(3):175-80.

67. Lee VA, Karthikeyan R, Rawls HR, Amaechi BT. Anticariogenic effect of a cetylpyridinium chloride-containing nanoemulsion. J Dent. 2010 Sep;38(9):742-9. 
68. Fard BK, Ghasemi M, Rastgariyan H, Sajjadi SH, Emami H, Amani M, et al. Effectiveness of Mouth Washes on Streptococci in Plaque around Orthodontic Appliances. ISRN Dent. 2011;2011:954053.

69. Willmot DR. White lesions after orthodontic treatment: does low fluoride make a difference? J Orthod. 2004 Sep;31(3):23542.

70. Okuda K, Adachi M, Iijima K. The efficacy of antimicrobial mouth rinses in oral health care. Bull Tokyo Dent Coll. 1998 Feb;39(1):7-14.

71. Femiano F, Lanza A, Buonaiuto C, Gombos F, Nunziata M, Piccolo S, et al. Guidelines for diagnosis and management of aphthous stomatitis. Pediatr Infect Dis J. 2007Aug;26(8):72832.

72. Barrons RW. Treatment strategies for recurrent oral aphthous ulcers. Am J Health Syst Pharm. 2001 Jan 1;58(1):41-50.
73. Westermeyer RR, Terpolilli RN. Cardiac asystole after mouthwash ingestion: a case report an review of the contents. Mil Med. 2001 Set;166(9):833-5.

74. Shulman JD, Wells LM. Acute ethanol toxicity from ingesting mouthwash in children younger than 6 years of age. Pediatr Dent. 1997 Sep-Oct;19(6):404-8.

75. Hornfeldt CS. A report of acute ethanol poisoning in a child: mouthwash, cologne, perfume and after-shave. J Toxicol Clin Toxicol. 1992;30(1):115-21.

76. Sperry K, Pfalzgraf R. Fatal ethanol intoxication from household products not intention for ingestion. J Forensic Sci 1990 Sep;35(5):1138-42.

77. Wennströn, JL. Treatment of periodontal disease in older adults. Periodontol 2000. 1998 Feb;16(1):106-112. 